\title{
A escrita SMS desde a perspectiva dos seus utentes. Unha achega sobre a lingua galega*
}

\author{
SMS writting from the perspective of its users. \\ An approach about the Galician language
}

\author{
Estefanía Mosquera Castro \\ Universidade da Coruña \\ Departamento de Galego-Portugués, Francés e Lingüística \\ emosquera@udc.es \\ [recibido 28/08/2012, aceptado 17/02/2013]
}

\section{RESUMO}

O presente estudo analiza as características das mensaxes de texto, unha das aplicacións das Tecnoloxías da Información e da Comunicación que máis crecemento está a experimentar e que se consolidou nos últimos tempos como un dos elementos comunicativos de maior expresividade da Era Electrónica. A nosa análise partirá das premisas da Lingüística Perceptiva e, a través dos resultados obtidos dun inquérito, daremos conta do que os galegos e as galegas xulgan sobre este medio de comunicación e sobre o sistema de representación da escrita -a linguaxe SMS- que a el xorde asociado. Tamén determinaremos -segundo as súas consideracións- o perfil das persoas usuarias, as razóns fundamentais que motivaron o suceso desta ferramenta e a finalidade para a que se utiliza. E finalmente, realizaremos tamén unha aproximación ás propiedades lingüísticas que manifestan as SMS e estudaremos a súa consideración social e a súa proxección a outros ámbitos.

PALAbras ChaVe: mensaxes de texto, escrita SMS, Lingüística Perceptiva, lingua galega.

Mosquera Castro, E. (2013): “A escrita SMS desde a perspectiva dos seus utentes. Unha aproximación sobre a lingua galega”, Madrygal (Madr.), 16: 63-71.

\section{RESUMEN}

El presente trabajo analiza las características de los SMS, una de las aplicaciones de las Tecnologías de la Información y de la Comunicación que más crecimiento ha experimentado y que se ha consolidado como uno de los elementos comunicativos de mayor expresividad de la Era Electrónica. Nuestro análisis partirá de las premisas de la Lingüística Perceptiva y, a través de los resultados obtenidos de una encuesta, se examinará lo que los gallegos consideran sobre este medio de comunicación y sobre el sistema de representación escrita -el lenguaje SMS- que a él surge asociado. También determinaremos -según sus consideraciones-el perfil de las personas usuarias, las razones fundamentales que motivaron el éxito de esta herramienta y la finalidad para la que se utiliza. Y finalmente, realizaremos también una aproximación a las propiedades lingüísticas que presentan los SMS y estudiaremos cual es su consideración social y su proyección en otros ámbitos.

Palabras Clave: mensajes de texto, escrita SMS, Lingüística Perceptiva, lengua gallega.

Mosquera CAstro, E. (2013): "La escrita SMS desde la perspectiva de sus usuarios. Una aproximación sobre la lengua gallega", Madrygal (Madr.), 16: 63-71.

\begin{abstract}
This paper examines the characteristics of text messaging, the application of the Information and Communication Technologies which has experimented the fastest growing and which has established itself in recent times as one of the most expressive communicative elements of the Electronic Age. Our research parts from the premises of the Perceptive Linguistic and through the results of a survey we will indicate what the Galician judge on this means of communication and on the features of texting -SMS language- that comes associated with it. Alike, we will determine -according to their considerations- the profile of users, the main reasons that motivated the sucess of this tool and the purpose for which it is used. And finally, we will also carry out an approach to the linguistic properties of the SMS and, likewise, we will study its social status and its significance in other contexts.
\end{abstract}

KEY WORDS: text-messages, texting, Perceptive Linguistic, Galician language.

Mosquera Castro, E. (2013): "SMS writting from the perspective of its users. An approach about the Galician language", Madrygal (Madr), 16: 63-71.

* Este artigo enmárcase dentro do Programa de Formación de Profesorado Universitario (Orde EDU/3445/2011, de 30 de novembro). 
SUMARIO: 1 . As SMS no marco das TIC e dos seus utentes. 2. A nosa investigación. 2.1. Cuestións de método. 2.2. Resultados. 3. Conclusións. 4. Referencias bibliográficas.

\section{INTRODUCIÓN}

Este estudo ten como obxectivo principal realizar unha aproximación ao xénero electrónico das mensaxes de texto, que nace na década de 90 cando a industria da telefonía móbil -que tiña como finalidade a comunicación oral-desenvolveu esta aplicación. Inicialmente, o servizo de mensaxes curtas non estaba pensado para a interrelación entre as persoas usuarias de telefonía, mais como un medio a través do cal as compañías telefónicas informaban os seus clientes. A pesar da lenta progresión que experimentou nos primeiros anos (Crystal 2008: 4), a súa utilización a día de hoxe é masiva, nomeadamente entre a mocidade ${ }^{1}$; no entanto, a súa natureza funcional e expresiva favoreceu que se fixese extensíbel a outros grupos de idade, de forma que na actualidade constitúe un dos sistemas de comunicación máis empregados por toda a populación. Nestes medios, Teixeira (2008) afirma que os terminais móbeis desenvolveron tamén unha nova dinámica de escrita individual a través das mensaxes de texto, condicionada pola súa limitación a 160 caracteres.

As diferenzas a respecto doutros medios de interacción son múltiplas: en primeiro lugar, convén destacarmos a natureza instantánea do acto comunicativo, valor que nunha sociedade en constante transformación vira altamente atractivo. O tempo de produción e os custos son reducidos se comparados coa escrita tradicional: é doado chegarmos ao noso destinatario e non é preciso coñecermos a súa localización xeográfica concreta. E, de igual modo que acontece con outros sistemas de comunicación dixitais, as mensaxes de texto facilitan as interaccións sociais, xa que a través destes medios podemos transmitir todo o tipo de información sen a necesidade de nos expormos á presenza física do noso interlocutor. Noutras palabras, as SMS, embora sexan un soporte esencialmente gráfico, foxen das limitacións impostas polo proceso de escrita tradicional e, igualmente, posúen todas as vantaxes da comunicación oral sen os riscos da exposición pública. $\mathrm{Na}$ opinión de Castro (2008: 43) "diz-se o que não se tem coragem, facilitando a confissão sem o pudor ou o receio físico da exposição face-a-face".

Os seus condicionamentos técnicos -teclado abreviado, número restrinxido de caracteres por SMS e pantalla de tamaño reducido ${ }^{2}$ - e as súas propiedades -rapidez, instantaneidade, brevidade, localización e interactividade- configúranse como os factores fundamentais que condicionan o aparecemento dun novo sistema de representación da escrita en que a ortografía normativa se relaxa en función, en primeiro termo, da utilidade e, en última instancia, da expresividade (Mosquera Castro 2012). Quere dicir, a función principal deste medio é comunicar e non mostrar o que se sabe a través da escrita, se ben que moitas das estratexias que desenvolveron as persoas usuarias verifican un gran dominio do código lingüístico, como por exemplo o uso da puntuación para crear ícones que reflictan os estados de ánimo e as emocións -;), : : XD, :'(ou o emprego de números e símbolos con valor fonolóxico -m8 ('moito'), alg1 ('algunha'), ad+ ('ademais'), imx ('impor').

A Internet e a tecnoloxía móbil constitúen, en consecuencia, ámbitos onde se produciron fortes mudanzas no modo en que as persoas empregan a lingua para se comunicaren e, neste sentido, unha cantidade notábel de lingüistas e de docentes comezou a se preocupar polas posíbeis consecuencias que esta revolución tecnolóxica podía implicar na forma en que nos comunicamos nestes contextos. Así e todo, as

${ }^{1}$ Sobre esta cuestión, convén sinalarmos que do mesmo modo que acontece co emprego das Tecnoloxías da Información e da Comunicación, o sistema de mensaxes curtas e este tipo de escrita fíxéronse especialmente populares entre a xente nova, dado que as características deste medio o converteron nunha das formas de comunicación social máis atractivas para esta faixa etaria. Cfr. Prensky (2001).

${ }^{2}$ Sobre este particular, Teixeira (2008) afirma que son precisamente as condicións físicas da súa execución, co polegar nun teclado minúsculo e cun limitado número de teclas, as que van propiciar os procesos de maior alteración nas formas de escrita. Na mesma liña, Crystal (2008: 65) indica que "phones keep getting smaller and smaller, but fingers stay the same size". 
reflexións sobre as linguas non son exclusivas dos filólogos, mais tamén os utentes adoitan realizar observacións sobre os idiomas e sobre os seus falantes. Isto é, todas as persoas en certos momentos, somos teóricas da linguaxe, o que constitúe un dos esteos da Lingüística Perceptiva, disciplina que investiga a lingua mediante a pesquisa aos propios falantes sobre como senten ou perciben estes fenómenos ${ }^{3}$ (Sánchez Rei 2009: 250). Así as cousas, estas novas modalidades discursivas e a escrita abreviada que desenvolveron non supuxeron unha excepción e tamén foron albo das súas consideracións que, como poderemos comprobar ao longo deste estudo, varían substancialmente dunhas persoas para outras.

Diversos autores como Thurlow (2006), Crystal (2008) ou Castro (2008) -con quen concordamos-xulgan que as SMS achegan á xente nova un "medium that encourages them to explore and play about with the use of language at a time when they are still learning about correct punctuation, grammar and the overall structure of their syntax" (The Man of Txt 2005: 2). É dicir, a aparición de novos códigos amplía a gama de expresión da lingua e contribúe para a súa revitalización canto que se adapta ás novas necesidades e aos novos contextos de uso. Con todo, o catastrofismo adoita constituír unha tendencia con moitas adhesións, nomeadamente se vincularmos linguaxe e mocidade. En relación con isto, son moitas as persoas que se posicionan en contra deste sistema de representación da escrita, na medida en que consideran que estamos perante deturpacións da lingua estándar e que, consecuentemente, deben ser contestadas.

En definitivo, embora existan diversas investigacións que confirman que o emprego da escrita abreviada non entorpece a adquisición de destrezas, senón que favorece a súa competencia comunicativa (Ling 2002, Baron 2008 e Crystal 2008), e aínda que o seu estudo xa se está incorporando no ensino de linguas, nomeadamente nas aulas de ELE, as valorizacións sobre a linguaxe dos medios dixitais non cesan; en gran medida, este sistema de escrita aínda continúa a ser albo de moitas críticas que, na liña das que se indicarán neste traballo, tamén circulan a través de moitos blogs ou foros de discusión na propia rede ou mesmo a través de artigos de opinión nos xornais ${ }^{4}$.

\section{A NOSA INVESTIGACIÓN}

\subsection{CUESTIÓNS DE MÉTODO}

Para levar a cabo este traballo, decidimos realizar un cuestionario ${ }^{5}$ co obxectivo fundamental de comprobarmos cal é a opinión dos galegos e das galegas a respecto deste novo fenómeno lingüístico e comunicativo. $O$ inquérito foi difundido a través das redes sociais, nomeadamente Facebook e Twitter, o que nos permitiu chegar a un amplo abano de informantes de procedencia xeográfica moi diversa. O número total de persoas que realizaron o cuestionario foi de 237 , cifra que consideramos suficiente para os nosos datos seren representativos. Este inquérito consta de trinta e dúas cuestións - moitas delas vinculadas a través dunha relación de causaefecto-, en que se interroga as persoas sobre diversos aspectos relacionados coas SMS, a escrita reducida e a súa consideración social.

As preguntas preséntanse en diversas modalidades -escolla entre varias opcións, texto libre, respostas fechadas de 'si' ou 'non', selección a partir dunha listaxe, etc.- de modo que nin sempre é posíbel ofrecermos estatísticas. Igualmente, poden distinguirse tres bloques fundamentais: unha primeira serie de preguntas en que se identifica o perfil das persoas que participan do cuestionario (grupo de idade, sexo e procedencia), unha segunda sección que se centra no xénero das mensaxes de texto (frecuencia de envío, razóns que motivan o seu uso, etc.) e a última, e máis extensa, que focaliza a súa atención no sistema de escrita abreviada (recursos lingüísticos, argumentos que apoian a súa utilización, caracterización dos utentes e valorizacións a respecto do seu uso e do seu futuro).

\footnotetext{
${ }^{3}$ Así, convén sinalarmos os estudos que sobre a lingua galega se teñen levado a cabo neste ámbito da lingüística perceptiva, cal Kabatek (2000) ou Iglesias Álvarez (2003).

${ }^{4}$ Cfr. http://conciencia20.pd2.iup.es/2011/02/17/cara-y-cruz-del-uso-del-lenguaje-sms/.

${ }^{5}$ Accesíbel na seguinte ligazón en Google Docs.: https://docs.google.com/spreadsheet/viewform?pli=1\&f ormkey=dGo3QW54Z3huNUt1VllaVmxDUFF1Snc6MQ\#gid=0.
} 


\subsection{RESULTADOS}

Como indicamos en $\S 2.1$, o primeiro bloque de preguntas estaba destinado a determinar o perfil das persoas que preencheron o inquérito coa finalidade de verificarmos se este abarcaba ou non un amplo sector da populación galega e, por tanto, se os resultados que obtivésemos poderían ser simbólicos do parecer xeral -embora sexamos conscientes de que existirán diverxencias entre uns colectivos e outros e mesmo dunha persoa para outra. En relación á idade, estabelecemos tres faixas, 15-25, 26-40 e +40 e convén sinalarmos que as estatísticas que obtivemos a respecto dos nosos informantes en relación ao grupo foron as seguintes: $28 \%, 46 \%$ e $26 \%$ respectivamente. A respecto do sexo, contamos cunha participación moito maior das mulleres que constitúen o $60 \%$ da nosa mostra. Será no referente á procedencia onde acharemos unha gran diversidade, sobrepasando mesmo os límites xeográficos da Galiza. Así, das 237 enquisas, 153 foron feitas por informantes da Coruña -cidade desde a cal se divulgou o inquérito-, 36 de Pontevedra, 32 de Lugo, 8 de Ourense, e outras 8 de zonas moi diversas, cal Barcelona, Madrid, León, Las Palmas ou mesmo Irlanda e Angola, o que máis unha vez demostra a natureza deslocalizadora dos medios de comunicación electrónicos.

Unha vez determinado o perfil das persoas que cubriron o inquérito, convén centrármonos agora nos datos referentes ao sistema de mensaxes curtas. Neste sentido, o 91\% das persoas afirma utilizar este medio de comunicación con certa frecuencia, en canto o $9 \%$ asegura non usalo ou facelo de forma residual. Entre aqueles individuos que si que adoitan enviar mensaxes de texto existe certa diversidade a respecto da cantidade diaria. Así, o $51 \%$ dos informantes di que costuma enviar entre unha ou dúas mensaxes por día, mentres que un 25\% declara redixir máis de dez. Entre estas cifras, sitúanse aqueles que envían máis de tres -o 14\%-e máis de $5-011 \%-$, como se deduce da seguinte gráfica:

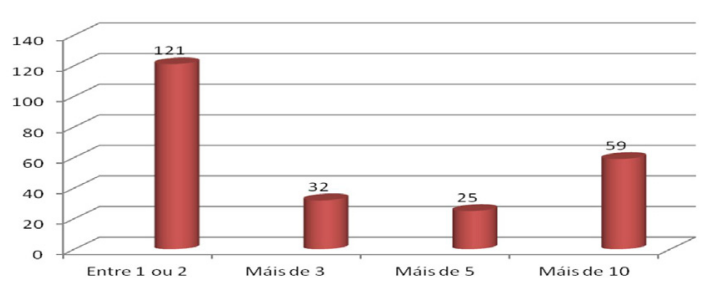

Fig. 1. Frecuencia diaria de envío de SMS

En base a estes datos, verificamos un uso masivo deste sistema de interacción por parte de todos os grupos de idade, se ben que canto maior é a idade das persoas usuarias, menor é a cantidade de SMS enviadas ${ }^{6}$. Sobre esta cuestión, facemos nosas as seguintes palabras de Crystal (2008: 89):

The conventional wisdom is that it's a teenage thing; and indeed, the surveys do show a huge bias in that direction. As early as 2002 in the UK, it was being reported that text messages had replaced phone calls as the commonest use of a mobile phone, and that the younger you are the more likely you are to text. A report in 2003 by mobile phone insurer CPP (Card Protection Plan) Group said that 80 per cent of under-25s texted rather than called. On the other hand, so did 14 per cent of people over 55. Plainly, youth isn't the only factor. And in 2006, a survey by the UK regulatory body Ofcom (Office of Communications) reported that adults as a whole in the UK made on average twenty phone calls a week, but sent twenty-eight text messages. It is a global trend, which was being repeatedly seen in the early years of the new millennium.

A respecto das razóns que xustifican o emprego das SMS, Varshinskaya (2002: 148) estabelece a seguinte listaxe: i) é moito máis barato que telefonar, nomeadamente cando se envía unha SMS ao estranxeiro; ii) por tanto, é un modo de os interlocutores aforraren cartos; iii) constitúe unha maneira confidencial de pasar a información e ofrece a posibilidade de realizar comunicacións secretas ou cando menos cun alto nivel de privacidade - que algunhas culturas como a xaponesa valoran de forma positiva-; iv) é máis eficaz para deixar unha mensaxe que non é urxente, cando non queremos distraer a

\footnotetext{
${ }^{6}$ De feito, o $69,3 \%$ das persoas que se inscriben no grupo de idade +40 adoitan enviar entre unha ou dúas mensaxes diarias, en canto o $11 \%$ sinala que redixen máis de 10 SMS por día. Esta cifra ascende ao $13 \%$ na faixa etaria de 26-40 e chega na populación máis nova (15-25) ao 24\%. Por seu turno, o $91 \%$ de todos os informantes concorda en que o sector que máis emprega esta tecnoloxía é a mocidade.
} 
outra persoa, ou cando non se nos permite realizar chamadas ${ }^{7}$; vi) é útil cando se precisa gardar silencio ou cando o ambiente é ruidoso e non permite a conversa; e vii) configúrase, en ocasións, como unha forma de diversión, especialmente entre os máis novos ${ }^{8}$.

As persoas que foron entrevistadas no noso traballo -o 55\% das cales afirman preferir este medio para interaxiren en lugar doutros sistemas de comunicación- achegan, na liña da clasificación anterior, os seguintes motivos por orde de preferencia: i) é económico $(39 \%)$, ii) é rápido $(36 \%)$, iii) é menos molesto $(28 \%)$ e iv) ten unha duración controlada $(8 \%)^{9}$.

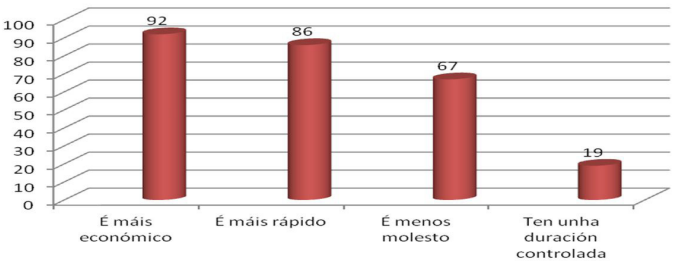

Fig. 2. Razóns que motivan o envío de SMS

Nesta pregunta, deixamos un espazo para que os informantes puidesen achegar tamén algunhas outras funcionalidades, non contempladas no formulario. Entre as principais, destacan que se trata dun medio máis íntimo, que non require a dispoñibilidade dos interlocutores e que as mensaxes poden lerse cando as persoas así o decidiren, para alén de permitiren envíos a máis de un destinatario. No lado oposto, o $45 \%$ das persoas para as cales non constitúe o seu medio de comunicación habitual achega argumentos que fan referencia á natureza impersoal do medio, á pouca información que pode transmitir, á falta de hábito e á preferencia por outros sistemas de interacción, nomeadamente a conversa presencial, o telefone ou o correo electrónico.

No que respecta á finalidade das mensaxes de texto, vira necesario repararmos en que as SMS de carácter persoal constitúen o tipo de interacción máis frecuente, de modo que o $75 \%$ das persoas entrevistadas afirma utilizar este servizo para se relacionar coas súas amizades e coa súa familia, en canto o $56 \%$ acha que constitúe, igualmente, un medio idóneo para o envío de información. En menor medida, tamén se adoita empregar para realizar determinadas xestións ou trámites de tipo comercial ou profesional $(6 \%)$ e para participar en concursos ou programas televisivos e radiofónicos (1\%). Un $2 \%$ dos informantes engade outros usos, cal a transmisión de datos moi concretos ou o estabelecemento de relacións de natureza íntima.

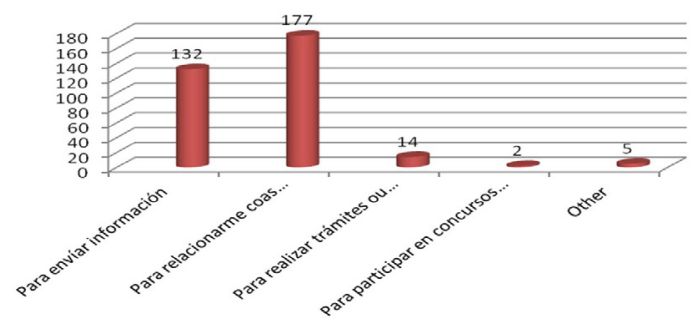

Fig. 3. Finalidades das mensaxes de texto

No tocante ao sistema de escrita empregado na fase de produción das SMS, o 59\% das persoas que realizou o inquérito afirma utilizar diversos recursos de abreviación, dado que isto lle permite exprimir unha maior cantidade de información nun espazo que, do punto de vista tecnolóxico, é reducido. E embora enunciásemos

${ }^{7}$ Crystal (2008:94) indica que as mensaxes de texto permiten realizar unha comunicación de forma discreta, se se tiver o telemóbel en modo silencio; para alén disto, sinala que "in 2007, commercial trials were being conducted by Australian airline Qantas into the possible use of Inmarsat-routed SMS text messaging on their planes. The 12-month trial allowed passengers on a Boeing 767 to send text messages or emails but not voice calls, to avoid disturbing other passengers".

${ }^{8}$ Ling (2002: 42), nunha clasificación similar para as chamadas, sinala que o envío de mensaxes de carácter xocoso por voz, cal as brincadeiras, é escaso ou nulo, dado que, segundo este autor, existe unha longa tradición que considera tales chamadas como inapropiadas ou mesmo perigosas. En contraste, moitas das persoas entrevistadas para o seu estudo afirman que enviaban con certa frecuencia mensaxes de texto deste tipo. Tamén Crystal (2008: 94) sinala que "the value of the medium for people -old as well as young-who want to communicate secretly or subversively is also apparent".

${ }^{9}$ Convén subliñarmos que as porcentaxes reflectidas nas gráficas poden sumar máis de $100 \%$, dado que nalgúns casos os informantes tiñan a posibilidade de seleccionaren máis dunha opción. 
máis arriba que este sistema de escrita deriva inicialmente da necesidade de se adecuar aos 160 caracteres, coidamos que é mais correcto indicarmos que as condicións en que naceron as SMS favoreceron o incremento dunha linguaxe máis simplificada (48\%) e que agora son as súas vantaxes -rapidez nas comunicacións (43\%) e expresividade $(11 \%)$ - as que estenden esta modalidade gráfica, como así o demostra a súa presenza noutros ámbitos, cal o correo electrónico, os chats ou as novas aplicacións de mensaxes de texto en que non existe limitación de espazo. En relación ás estratexias lingüísticas que utilizan para viraren as súas interaccións máis dinámicas é preciso repararmos na seguinte gráfica:

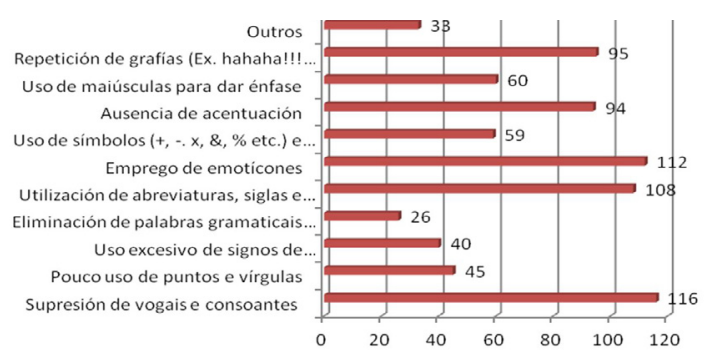

Fig. 4. Recursos lingüísticos presentes nas SMS

Como se deduce desta figura, os recursos máis empregados na linguaxe das mensaxes de texto son, por un lado, os emotícones, pois de igual modo que os elementos paralingüísticos presentes nas conversas presenciais, contribúen para interpretarmos o sentido do texto e para expresarmos o estado de ánimo ao noso interlocutor. Por outro lado, o uso de abreviaturas e a supresión de vogais e consoantes doadamente recuperábeis polo contexto constitúen outra das estratexias máis recorrentes na escrita SMS, debido ás limitacións de espazo a que xa fixemos referencia. Cunha menor incidencia, a repetición de grafías ${ }^{10}$ e o emprego das maiúsculas e de signos de puntuación son tamén relevantes, dado que permiten -de modo similar aos emotícones- dotaren de expresividade o texto e compensaren a distancia física que separa os interlocutores. Por súa vez, o $67 \%$ mantén neste tipo de escrita os trazos lingüísticos propios da súa zona, e un $22 \%$ dos infomantes sostén que mestura o galego e o castelán cando redixe as súas mensaxes. A razón fundamental que aducen a este respecto é a súa funcionalidade, pois en ocasións unha lingua permite abreviar máis do que outra. Con todo, o sarcasmo, a ironía e a expresividade son tamén algúns dos argumentos con que as persoas entrevistadas xustifican este fenómeno.

Neste contexto de diversidade lingüística, a introdución de estranxeirismos é abalada polo $46 \%$ dos informantes. A motivación principal neste caso tamén é a funcionalidade, sobre todo no referente á lingua inglesa, que desenvolveu un gran número de abreviaturas para estas esferas entre as cales destacan as seguintes: LOL ('Laughing Out Loud' ou 'Rindo sen parar'), BTW ('By The Way' ou 'Por certo'), CUL ('See you later' ou 'Vémonos despois'), BRB ('Be Right Back' ou 'Volto nun anaco'), OMG ('Oh my Good' ou 'Ai, meu Deus') e T2YL ou TTYL ('Talk to you later' ou 'Falamos máis tarde'). Igualmente, a diversión, a expresividade, a moda e a complicidade co noso interlocutor constitúen tamén argumentos que acreditan a súa presenza.

No que respecta ao perfil de quen emprega a escrita SMS, convén sinalarmos que, grosso modo, coincide con aquel que trazamos para o das persoas usuarias deste sistema de interacción. Así as cousas, o 97\% dos individuos entrevistados concorda en que o sector que máis utiliza esta modalidade lingüística é o da xente nova; por outro lado, o $74 \%$ considera que non existen diferenzas significativas no uso en relación ao sexo, en canto o $22 \%$ xulga que son as mulleres as que máis o utilizan. Alén disto, o $86 \%$ dos informantes asocia este tipo de escrita con contextos de uso informais e afirma modificar a súa lingua en función da persoa a que vai dirixida a mensaxe, embora haxa individuos que costuman estender estas prácticas a todos os ámbitos, sen excepcións (5\%). Neste sentido, ao $52 \%$ dos nosos informantes - usuarios ou non-,

${ }^{10} \mathrm{Na}$ opinión de Anis (2006: 4), “les caractéristiques formelles de cet écrit sont l'oralité (les effets d'oralité en fait), l'abréviation et l'iconicité (notamment a travers les émoticônes), ces caractéristiques peuvent entrer en contradiction. Ainsi les étirements graphiques (voir plus loin), phénomène d'iconicité, offrent un contraste évident avec les abréviations". 
non lle incomoda recibir SMS que empreguen este sistema de escrita abreviada, dado que unha vez que se acostuman vira doado percibiren os textos e porque, nalgúns casos, tamén descifraren o contido das mensaxes se converte nunha actividade lúdica. Non obstante, o outro 48\% acha que este modalidade gráfica atenta contra a gramática, dificulta a lectura e require uns custos de tempo maiores para se poderen interpre$\operatorname{tar}^{11} \mathrm{e}$, por tanto, non gosta de recibir esta clase de mensaxes cifradas, que para non poucas persoas constitúen auténticos xeróglifos.

E se ben que o $59 \%$ das persoas declaraba utilizar diversos mecanismos de abreviación, o $56 \%$ xulga que empregarmos a linguaxe SMS neste medio pode ter consecuencias negativas no nivel de competencia escrita, pois, na súa opinión, contribúe para potenciar tendencias de mal uso xa existentes, especialmente entre a mocidade. Do mesmo modo, tamén sosteñen que pervirte a lingua canto que acaba por automatizar diversos erros ortográficos e que, por tanto, emprobrece a expresión escrita. Xa Thurlow (2006) compilou hai case unha década críticas similares que acabaron por xerar un sentimento de pánico moral na populación e, de acordo con Crystal (2008:8), "there is now a widespread folk belief that, whatever texting is, it must be a bad thing" ${ }^{2}$. No entanto, o restante $44 \%$ considera que as características desta linguaxe presupoñen un coñecemento previo e consolidado da compoñente gramatical e ortográfica da lingua de partida e non á inversa e, ao mesmo tempo, acrecentan que agudiza o enxeño e que contribúe para a normalización das linguas, pois reflicte a súa capacidade para se acomodaren a novos espazos. Este grupo repara tamén en que a razón que está detrás dunha má competencia é a falta de destreza no proceso de lectura e de escrita.

Nunha liña similar encóntranse as consideracións a respecto da incorporación desta linguaxe ao ensino de linguas, aínda que neste punto predominen as valoracións negativas -que se reafirman nos argumentos achegados para a diminución da competencia escrita-, dado que só un $28 \%$ xulga conveniente introducir nas aulas a tal modalidade de expresión. Con todo, as valorizacións en afirmativo parecen abrir unha nova perspectiva desde a cal nos achegarmos a este fenómeno. Así, consideran necesario atendermos ás prácticas reais que se producen na sociedade e entenden que estamos perante unha modalidade discursiva que se sitúa moi próxima da faixa etaria do alumnado de secundaria, coas posibilidades que isto ofrece. Na súa opinión, trátase de ponderarmos os vínculos entre a reflexión en lingua e o contexto sociocultural en que nos achamos. Para alén disto, permite aproximármonos de moitos trazos da nosa lingua, dado que os recursos que emprega esta linguaxe afectan todas as áreas da gramática e favorecen a participación e o interese do estudantado, verdadeiro protagonista da evolución lingüística.

De entre o $60 \%$ que afirma coñecer outros contextos en que esta linguaxe é utilizada, a maior parte das persoas sinala fundamentalmente os demais medios de interacción electrónica -cal os chats, a mensaxaría instantánea, o correo electrónico ou as redes sociais- e a recollida de apuntamentos. No entanto, parece descoñecer -salvo algunha excepción- outros ámbitos que están a tirar rendibilidade das funcionalidades que achega este sistema de escrita abreviada, como o da publicidade que adopta a orixinalidade, a creatividade e a suxestividade desta linguaxe para exprimir o máximo posíbel nun espazo reducido e para captar a atención do público; ignoran tamén a súa presenza no campo literario, onde nos últimos tempos cobraron bastante suceso as novelas por entregas, enviadas a través de mensaxes de texto, ou mesmo aquelas que en formato libro están redixidas en linguaxe SMS ou que incorporan na súa trama argumental certos textos nesta modalidade

${ }^{11}$ A respecto dos custos e das vantaxes cognitivas no proceso de produción e de interpretación da linguaxe SMS, véxase Perea / Acha / Carreiras (2009: 52).

${ }^{12}$ Segundo John Humphrys (2007), as persoas que escriben en linguaxe SMS son "vandals who are doing to our language what Genghis Khan did to his neighbours eight hundred years ago. They are destroying it: pillaging our punctuation; savaging our sentences; raping our vocabulary. And they must be stopped". 
de escrita (como acontece na obra de Patricia Casas Vázquez Teselas de cidade, publicada en 2007, ou na de Marilar Aleixandre $O$ coitelo en novembro, dada a lume en 2010).

En relación ao futuro que as persoas con que traballamos desexan a este sistema de escrita, existen diversas opinións: por un lado, achamos un sector importante que vaticina que acabará por dexenerar a linguaxe estándar e que aumentará as confusións ortográficas afectando a coherencia dos textos, sobre todo na xente nova; neste sentido, afirman que é preciso tomarmos medidas para frearmos esta tendencia, embora xulguen que o seu uso descenderá conforme aumentar a idade. Por outro lado, encóntranse as impresións de quen considera que se trata dunha variedade escrita de gran suceso na actualidade e que permanecerá asociada a contextos informais e comunicativos en que prime a velocidade e a instantaneidade das interaccións. E, en último lugar, sitúanse aquelas persoas que pensan que como consecuencia do aparecemento de terminais móbiles con teclado querty e de tecnoloxías da comunicación gratuítas e sen limitacións de espazo - como o Whatsapp ou o Line- esta escrita simplificada está condenada a desaparecer.

\section{CONCLUSIÓNS}

Como puidemos comprobar ao longo das páxinas que preceden, o rápido desenvolvemento das tecnoloxías da comunicación a través da rede e da telefonía móbil, deron lugar a novos medios de interacción, entre os cales o sistema de mensaxes curtas alcanzou unha gran proxección grazas a factores como a rapidez, a interconectividade, a brevidade e o seu baixo custo, o que o se torna moi importante no caso dalgúns grupos etarios, como o da mocidade. Por súa vez, o suceso das mensaxes de texto e as propiedades técnicas dos terminais móbiles e da propia aplicación tamén contribuíron para acelerar un proceso revolucionario na escrita de gran magnitude; nestes medios, convén repararmos en que se trata dun fenómeno universal que, revestido de diferentes mecanismos de redución, é común a todas as linguas. E se ben que xurdiu como consecuencia das limitacións de espazo que posúe a tal ferramenta, acabou por se estender a outros sistemas de interacción electrónica sen este tipo de restricións, mais onde tamén priman valores como a velocidade, a expresividade e a instantaneidade. Por tanto, as repercusións -fortemente mediáticas- que provocou este sistema de escrita propiciaron que se convertese nun dos temas máis actuais do debate lingüístico.

Así, moitos académicos e lingüistas xa mostraron o seu desasosego - con frecuencia sen demasiados datos que avalasen as súas inquietudes- polo uso indiscriminado de abreviaturas e de emotícones, importante por ser a xente nova a protagonista desta para-ortografía. Con todo, esta cuestión non só espertou a curiosidade, a fascinación ou os medos das persoas expertas en materia de lingua, mais tamén dos propios utentes, o que provocou que se crease toda unha mitoloxía arredor deste fenómeno que profetizaba todo o tipo de desastres lingüísticos, os cales, como puidemos verificar, aínda se manteñen como unha percepción en bastante xente. Os datos achegados neste estudo apoian fundamentalmente estas teses apocalípticas, se ben que tamén existen consideracións máis positivas na liña do que os estudos máis recentes parecen evidenciar, isto é, que tan só constitúe unha nova modalidade de escrita e que favorece a competencia escrita e fomenta a creatividade lingüística dos seus utentes. En definitivo, este artigo tencionou demostrar que o pensamento popular pode chegar a exercer unha enorme influencia na caracterización de fenómenos lingüísticos, como acontece coa linguaxe SMS.

\section{REFERENCIAS BIBLIOGRÁFICAS}

ANIS, Jacques (2006): “Communication électronique scripturale et formes langagières", en Portal de Investigacións humanisticas da Universidade de Poitiers. Dispoñíbel en: http://rhrt.edel.univpoitiers.fr/document.php?id=547 (consultado en 19/01/2012).

Baron, Naomi (2008): Always on. Language in an Online and Mobile World. Oxford: Oxford University Press. 
CAstro, Teresa (2008): Quando as Teclas Falam, as Palavras Calam. Estudo sobre a Utilização do Telemóvel e do Messenger por Crianças do $5^{\circ}$ e $6^{\circ}$ Ano do Distrito de Braga. Universidade do Minho: Instituto de Estudos da Criança.

Crystal, David (2008): Txtng: The Gr8 Db8. Oxford: Oxford University Press.

Iglesias Álvarez, Ana (2003): Falar galego. no veo por que: Aproximación cualitativa á situación sociolingüistica de Galicia. Vigo: Xerais.

HuMPHRYs, John (2007): "I h8 txt msgs", en Daily mail (28/09/2007).

KABATEK, Johannes (2000): Os falantes como lingüistas. Tradición, innovación e interferencias no galego actual. Vigo: Xerais.

LiNG, Rich (2002): “Chicas adolescentes y jóvenes adultos varones: dos subculturas del teléfono móvil", Estudios de Juventud 57, pp. 33-46.

Mosquera Castro, Estefanía (2012): "Novos retos da Lingüística: as textualidades electrónicas. Consideracións sobre a escrita dos chats e das SMS", LLJournal 7. Dispoñíbel en: http://ojs. gc.cuny.edu/index.php/lljournal/article/view/1147/1250 (consultado en 16/07/2012).

Prensky, Marc (2001): "Digital Native, Digital Inmigrants", On the Horizon 9/5. Dispoñíbel en: http://www.marcprensky.com/writing/prensky $\% 20-\% 20$ digital $\% 20$ natives, $\% 20$ digital $\% 20 \mathrm{im}$ migrants\%20-\%20part1.pdf (consultado en 19/07/2011).

SÁnchez Rei, Xosé Manuel (2011): Lingua galega e variación dialectal. Ames: Laiovento.

Teixeira, Jose (2008): "Língua Portuguesa e as Novas Tecnologias de Comunicação: as dinâmicas da(s) escrita(s)", Diacrítica Série Ciências da Linguagem 22/1, pp. 107-127. Braga: Centro de Estudos Humanísticos da Universidade do Minho.

The Man Of Tхт (2005): “Are text messages making us iliterate?”. Dispoñíbel en: http://txt2nite. com/forum/viewtopic.php?t=43 (consultado en 20/04/2011).

Thurlow, Crispin (2006): "From statistical panic to moral panic: The metadiscursive construction and popular exaggeration of new media language in the print media", Journal of ComputerMediated Communication 11/3. Dispoñíbel en: http://jcmc.indiana.edu/vol11/issue3/thurlow. html (consultado en 26/07/2012).

VARSHINSKAYA, Olga (2002): "Comunicación móvil como fenómeno social: La experiencia rusa", Estudios de Juventud 57, pp. 139-149. 